\title{
Cradles to Cradles: Designing for Non-Human Loops
}

\author{
LEONARD D. YUI \\ Roger Williams University
}

Cradle to Cradle (C2C) sustains anthropocentric ideals that do little to recognize the immediate uses and needs of nonhuman species and processes. A new more comprehensive model is proposed here that echoes the ethical and architectural imperatives of the original $\mathrm{C2C}$ model, while also providing a more ecologically inclusive perspective for designers. The study begins by highlighting the origins of C2C through the works of Stahel/Reday and McDonough/ Braungart and others that define a sustainable trajectory that is largely contingent on benefiting human productivity. The simplification of material ends are hastened for future production and economic gain. A reciprocal investigation into non-human uses of wood illustrate its diverse functions, such as a place to nest or to take cover, which slows and expands entropic engagements. The term "deadcycle" is used to underscore entropy and to shift away from a product lifecycle perspective. These ecological insights are drawn from forest researchers studying the science of deadwood, which highlight complex theories surrounding disturbance and disequilibrium. The ecological concepts of "biological legacy" and "multiple users" reveals a shared world where ownership is fluid and borrowing is essential. These themes help to conceive an ideal ecological loop(s) model presented here as "cradles to cradles."

\section{INTRODUCTION}

"Cradle to Cradle" (C2C) has become a foundational sustainability concept in architecture. The proliferation of programs like LEED and Life Cycle Analysis are increasing the momentum toward maximizing reuse, recycling and more importantly to, firstly, hasten compatibility of materials for the design and manufacturing phase. The chemist, Michael Braungart, and architect, William Mcdonough, promote a more encompassing ethical model that goes beyond the simple tendency towards "eco-efficiency" (cradle-to-grave), to one that is "eco-effective," (C2C). ${ }^{1}$ Their aim to is to recondition industrial systems to "ensure the availability" of raw materials by valuing them as "nutrients" and follow "metabolic" processes. ${ }^{2}$ But does such assurances reduce the insatiable trajectory of human consumption? Or does such streamlining actually pressure designers to look over ecological processes that require more time to express themselves?

The C2C model has been inspired by ecology, but it was conceived for industry, i.e. for anthropocentric productivity. Instead, a more inclusive model with non-human species and processes requires a more equitable, albeit more complex, notions of prosperity - even ones that may be unbeneficial for humans. As topics on landscape and ecology bear ever deeper into the architectural dialog, an opportunity remains about how to adapt the fundamental tenants of architectural sustainability - energy and material conservation - to include more direct and creative engagements with wildlife and their systems.

The current model aims to address human environmental problems, and presumes the natural world will resolve itself as our shadow - still and without agency. A deeper reciprocity with an ecological world requires acknowledging what the environmental philosopher David Abram describes as "animateness of perceived things." ${ }^{3}$ A rethinking demands acknoweldging a more aggressively negotiated world where other species' loops may directly intersect, animate or disrupt our own. If the current end-use model is represented by a linear line toward the landfill and the sustainable paradigm by a perpetual loop, then this paper proposes to clarify a model where many material loops intersect one another to increase broader use-opportunities and to engage more directly with current ecological dialogs (Fig 1).

The following exploration will first clarify the key intentions and origins of the $\mathrm{C} 2 \mathrm{C}$ model and their industrial and economic roots. Secondly, the natural world, as presented through the ecological sciences, is studied with the aim to illustrate an ideal ecological loop for comparison. Both studies use the material of wood as a device for comparing perceptual differences in the urban versus ecological settings.

\section{A SUSTAINABLE PARADIGM: TOWARD A PERPETUAL HUMAN EXISTENCE}

A closer inspection of $\mathrm{C} 2 \mathrm{C}$ origins reveal a particular philosophy and trajectory behind the simple circular form. A significant point is the attempt to associate sustainable practices to economic gains. Materials are isolated from the natural processes and are adapted to quickly fold back into the cyclical system. What emerges from these and other diagrams are some basic phases: the pre-use, use, and postuse phases (Fig 3). The evolution of $\mathrm{C} 2 \mathrm{C}$ has complicated these phases over the years, yet the primary components largely remain identifiable and is especially helpful later on to organize where certain emphasis is placed. 
CURRENT PARADIGM

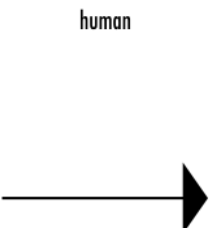

"CRADLE TO GRAVE"

"CRADLE TO CRADLE"

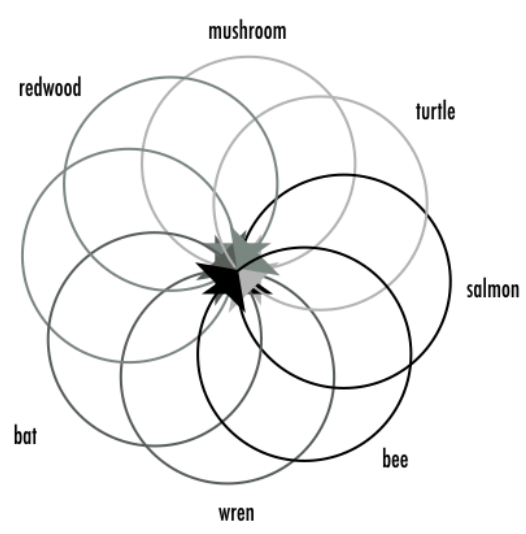

CRADLES TO CRADLES

\section{LINEAR USE-EXTENSION}

Some of first modern principles for the $\mathrm{C} 2 \mathrm{C}$ model were laid by a Swiss architect Walter R. Stahel and Genevieve Raday in the seventies and eighties and has had a significant influence in the world of sustainable design, production and waste management. Stahel's influential paper titled, "ProductLife Factor" details more clearly the intents of a circular economy - one where a C2C ideals spurs jobs and industry. Stahel advocates the act to "reuse, repair, reconditioning, and recycling" will lead to "increasing the number of skilled jobs available... reducing dependence on strategic materials... (and providing) the private sector with fresh impetus to make cheaper goods." ${ }^{4} \mathrm{C} 2 \mathrm{C}$ was conceived within, and sustains, the existing economic framework by tying jobs to sustainable practice, which made its influence far more significant. Stahel envisions a "spiral-loop" that offers repeatable economic opportunities (Fig 2).

Stahel's diagram focuses on the "product-life," which he defines as, "the period over which products and goods are used, (and)governs their replacement speed." He believes that the cradle-to-grave model shortens product-life and increases "demand for replacement goods," but an extension optimizes the "total life-span of goods... (and) increased wealth... toward a sustainable society." ${ }^{6}$ The "spiral" is meant to extend use, slowing the replacement speed of raw materials, and the increase of manufacturing of products in between. The elongation benefits the economy because there are potentially more points at which humans can gain from the re-manufacturing process. He compares it to the "car mechanic," where shops have emerged in dispersed, as needed, patterns from increased demand.

Unfortunately, many benefits of Stahel's spiral model arise from making the linear process simply longer, not necessarily to upend the cradle-to-grave process. The implied claim that demand for goods - or consumerism - would drop seems unfounded, especially since his model relies on the economic activity that then depends on increased consumption. There is no logical mechanism described to slow demand or how to address the rapid technological development that would intensify after the eighties. And with the advent of roughly 3.5 billion more people on the earth since his early writings, the increase of recycling and reuse has been primarily addressed through large industrial, mostly mechanized, waste management facilities.

Even if raw materials are "saved" or "optimized" with this system, it is questionable whether they benefit non-human systems as Stahl's argument seems to imply. Rather it is more likely natural areas function as storehouses for later human resources, which leaves room for exploitation. Salvage logging, for example, is often justified as providing ecological benefits, yet forest scientists negate that such evidence of benefits have ever existed. ${ }^{7}$ The limitation of human impact does not necessarily indicate ecological health or proof that efficiency is beneficial.

\section{CLOSING THE LOOP QUICKLY}

The Mcdonough/Braungart C2C model builds on prior works, but brings attention to the post-use phase. Their biomimetic approach looks to how "nature operates according to a system of nutrients and metabolisms in which there is no such thing as waste." ${ }^{8}$ Their mantra of "waste = food" strives to reconsider how the ends can change how manufacturing and design are conducted. For example, the avoidance of

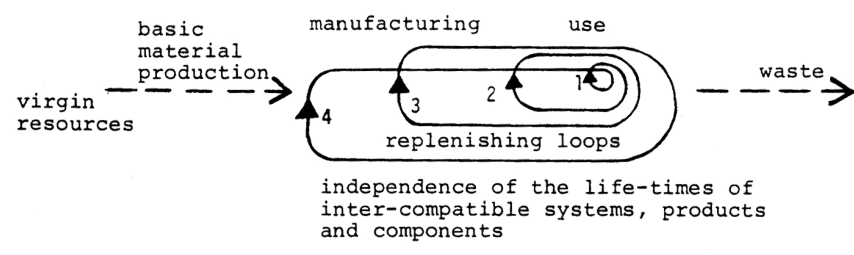

Figure 2: Stahel's "Self-Replenishing System: Product-Life Extension." 
"monstrous hybrids" - materials so intermixed they are difficult to separate for reuse - reveals opportunities to rethink manufacturing or to redesign products so that they are more easily recyclable. If Stahel's product-life is primarily about how the pre-use and use phase can be extended for economic benefit, then the Mcdonough/Braungart C2C model is about how the post-use phase can hasten and inspire more ecologically beneficial pre-use processes.

The Ellen Macarthur Foundation report from 2013 titled "Towards the Circular Economy: Economic and Business Rationale for an Accelerated Transition," provides one of the most current and detailed concept of how product-life diagram has evolved. This text was developed by leading team of researchers that included both Stahel and Braungart. Most of essential parts remain the same with a noticeable delineation between the biological and human processes.

Overall the updated model shares many qualities of Stahel's original spiral diagram, but notably includes how the end-use process, and the focus on nutrients, can aid in the production of more cycles. On the technical human side, this means emphasizing processes such as "standardization," "modular design," and "design for disassembly." ${ }^{9}$ On the biological side biochemic processes like composting and anaerobic digestion are used to attain "optimal biomass valorisation."10 They define this as way to "extract the maximum value from biomass waste before it is used for energy or soil restoration purposes." This includes the production of "fibers, sugars, and proteins and later plastics, medicines and fuels." These ideals are illustrated clearly in industries like urban wood waste products.

A forest service meta-analysis reveals $76 \%$ (47.7 million metric tons) of the urban wood waste is due to construction and demolition and other human wasted materials like furniture and cabinets etc. and about half is turned into biofuel mulch and engineered woods, while the other is sent to the landfill. ${ }^{11}$ The researchs shows how wood products like biofuel are solely generated for human benefits and, secondly, reveals how products are turned into highly refined pieces - particles - so it is readily translatable to other consumer products. Like flour for bread, the malleable shape of these materials allows manufactures to mold their products with glues into new forms like compressed firewood, OSB, particle boards and other engineered woods. $\mathrm{C} 2 \mathrm{C}$ may divert wood from the landfills, but it is also turning whole materials into industrial bits for the sole service of humans.

\section{WASTE = EVERYTHING}

Materials go from larger to smaller structures and at each transformation there is opportunity for economic gain. The process of valorization and the attempt to avoid the landfill reduces the material parts to only the bits and scraps before they are returned to nature as "nutrients." Meanwhile the

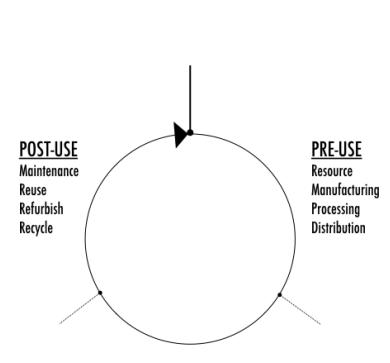

USE

CONCEPTUAL CONFIGURATION

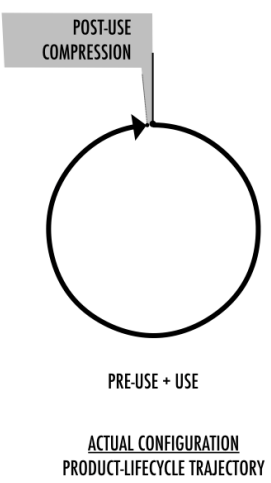

Figure 3: Cradle to Cradle Configuration, Conceptual vs Actual.

best parts of those materials, the large chunks - furniture, lumber, etc. - that embody many other non-human entropic processes are perceived with a human framework, even when they are unwanted.

Materials in the $\mathrm{C} 2 \mathrm{C}$ loop are ideally refashioned quickly and adapted to be easily repurposed back into the system. "Waste = Food," is a valuable metaphor, but overly simplifies a materials actual uses and ignores the many other embodied states of waste for others, such as a place for to rest or as a device for storage. "Waste = Just about everything," seems more representative of the true potential organic products. The focus on the theme of food/nutrients and the urgency to replenish the early stages for economic gain suggests a trajectory to compress the post-use phase (Fig 3). Its elimination through simplification echoes the business adage that "time is money." 12

C2C builds upon an important need to address energy and material issues in architecture. It begins to create a more convincing loop to help transition industry into one that mimics natural systems. Yet, its simplified expressions of nature have been cherry picked with economic sympathies, and as such maintains a trajectory of economic acceleration and isolation from more dynamic natural systems. What happens when non-human interests are elevated equally in the cycle? How do the other entropic stages elevate the ethical imperatives to build/design human and non-human relationships? The next section constructs an alternative model through an investigation of wood from an ecological perspective.

\section{AN ECOLOGICAL PARADIGM - THE DEADCYCLE}

"Deadwood" or "coarse woody debris" (CWD) displays many of the ideal benefits of an ecological open system. Additionally, its tangible and highly familiar example to architects and urban designers provide a direct model to rethink the nature of urban wood use and waste. "Deadwood," as its name would suggest, has long been culturally perceived as a negative object and is only beginning to make an impact in 
land management practices. The World Wildlife Fund (WWF) notes that,

"For generations people have looked on deadwood as something to be removed from forest, either to use as fuel, or simply as necessary part of 'correct' forest management....breaking up these myths will be essential to preserve healthy forest ecosystems and the environmental services they provide." ${ }^{13}$

Restoration ecologists, like Marzluff and Ewing, claim that a key element of urban habitat fragmentation comes from "remov(ing) and simplifying ground cover, trim(ming) branches from lower reaches of trees, cut(ting) down dead trees, and fastidiously rake, haul burn or grind up fallen dead materials. ${ }^{14}$ These sterile landscapes are preferred by human dwellers, yet they eliminate numerous important ecological places and processes for non-human benefits.

The interest in deadwood by the scientific community over the last thirty years is part of a continuing and dramatic paradigmatic shift in how scientist understand the ecological world. The ecologist Ronald Pulliam and Bart Johnson characterize the shift in ecological thinking as one from an equilibrium to disequilibrium point of view, "where history matters and populations and ecosystems are continually being influenced by disturbances." ${ }^{15}$ The ecological world is increasingly becoming much more complex to understand, with undefined trajectories and multiple perspectives, yet from a broader context it provides one of the most direct sources to understand the natural world and how humans fit within it. $\mathrm{C} 2 \mathrm{C}$ is influenced by the natural sciences through the abstraction of nutrient and energy cycling diagrams (ecosystem thinking, biogeochemical cycles, food webs, etc.) that have long been understood by scientists. However, a closer look at these diagrams reveals nuanced principles and details that have either been overlooked or due to a paradigm shift toward complexity is not addressed adequately.

Ecosystem models such as the one defined by H.T. Odum are not only primary inspirational sources to redirect material and energy flows, they are also suggestive of a drastically different world view that includes open systems and the exchange of materials between populations. Pulliam and Johnson criticize population ecologists for treating local populations as "autonomous units," and while ecosystem ecologists consider abiotic and biotic system components as "common currencies" between system boundaries. ${ }^{16}$ The concept of ecosystem theory is one among many others that are changing how we think about landscape cycles and include topics such as "predations theory," "keystone species," "island biogeography" and many others.

The C2C model attempts to mimic the circular ideals of energy and material processes, but as a model isolated to human flows during the use stage, it fails to acknowledge the intersection of other processes. The ecosystem diagrams shows the interconnected nature of species, rather than just their flows. "Herbivores," "carnivores," "decomposers" are the primary actors, for which humans are just a piece. However, an ecosystem diagram like this does not present specific ecological processes and values, and historical accounts. For this, it is helpful to look more carefully at how wood is an ultimate "common currency" that spans population borders, generations and activates ecological systems.

The table below shares a simplified list of ecological benefits of CWD developed by deadwood researchers. The list presents at least two important ways the processes of deadwood may challenge the current $\mathrm{C} 2 \mathrm{C}$ model. One is through the concept of "biological legacy" - a continuity through time - and another are the uses by a multitude of species.

\section{Ecological Benefits of Coarse Woody Debris ${ }^{17}$}

- Habitat

- Site for nests, dens and burrows

- Habitat for microbial decomposers

- A primary energy source for a complex food web

- Hiding cover for predators and protective cover for their prey

- Moist microsites

- Travel-ways across streams, across the forest floor, beneath and through the snow

- Refugia during disturbance and environmental stress

- Structure to slow stream flow and create pools

- Places for food to accumulate

- Cover from temperature extremes and predators

- Nitrogen fixation

- Accumulation of organic matter

- Increased ectomycorrhizal root tip associations

- Nutrient pool / storage

- Soil biology

- Carbon storage

- Regeneration

\section{Biological Legacy}

The first is the importance of time and how deadwood traverses through successional changes in the landscape. If the tree and its vibrancy in life represents the stages of succession - from field to forest - then deadwood in its death and entropy represents the equally important process of disturbance. As a byproduct of disturbance, deadwood presents a tangible way to see and engage historical ecological footprints. Because deadwood can last many years longer than successional and disturbance regimes in a forest, it acts as a stitch to interconnect these landscape stages. Scientists refer to this continuity as "biological legacy," which the Dictionary of Forestry defines as "a biologically derived structure or pattern from a previous ecosystem... often 
include large trees, snags, and down logs... to provide refugia and to structurally enrich the new stand." ${ }^{18}$ Deadwood may symbolize disruption, but its over-abundance, use and natural accumulation of rich nutrients is a significant net benefit to the ecosystem, which characterizes its foundational contribution to resilient places.

Biological legacy is especially useful because it prepares a place for the outcomes of several future trajectories involving a mixed cycle of succession and disturbance. The ecologist, C.S. Holling, states that a useful sustainable framework "embraces uncertainty and unpredictability. Surprise and structural change are inevitable."19 The concept of biological legacy emphasizes structure as a way to prepare and account for future disturbance events, which maybe particularly apt for the design field. Legacy - or the record of an extended end-use process - allows for the natural accumulation of redundant structures that is essential for ecological systems. This contrasts the current C2C's trajectory which was shown to compress the end-use cycle by quickly returning it to the beginning of the manufacturing cycle. The celebration of this latter extension of the biological "lifecycle" will be referred here to as a "deadcycle" in order to stress the largely disappearing pattern within urban places. A deadcycle reveals the embodied potential opportunity to sustain other lives after human use (see fig 4).

Lastly, legacy also shares how in some cases value is increased as the material is transferred from specie to specie. For example, wood peckers are considered primary cavity nesters because the holes they burrow provide homes that many other species depend on. The human ability to use and shape many kinds of wood in almost any way provides an opportunity to synchronize or to cultivate biological legacies between species. This accounts for multiple trajectories, and may even come to embrace them.

\section{MULTIPLE USERS}

Now that time has been extended, the second point helps to reveal what can fill that space. The world of deadwood reveals how its value arises from its collective role through time and structure. A set of prominent research ecologists explains that "structural attributes of forest stands are increasingly recognized as being of theoretical and practical importance in understanding and managing forest ecosystems. ${ }^{20}$ Since a piece of deadwood can be a large log, broken branches, rot wads etc., which are roughly the same material, the primary benefit instead arise from its diverse formal qualities. A standing dead tree or snag provides a growth substrate for fungus moss and lichen, spaces under bark for invertebrates to feed and take cover, birds like the nuthatch nest and roost by finding places to perch and even bats and martens can find places to serve as dens for resting and take cover from predators. ${ }^{21}$ Deadwood serves as a public park, providing diverse places for many species to commune at one time, and

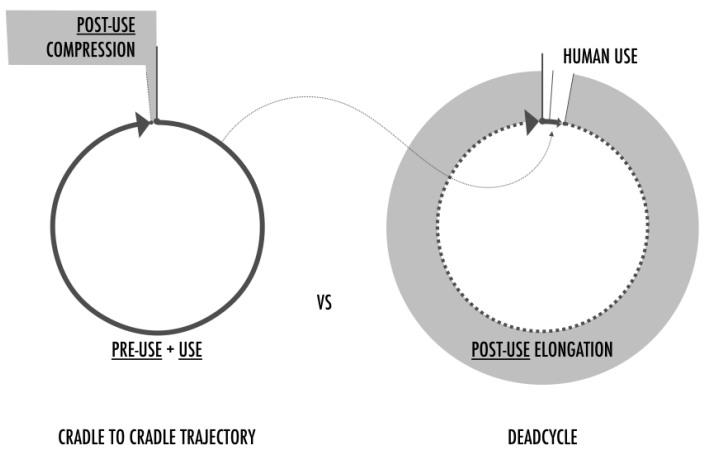

Figure 4: Deadcycle: End of Life Elongation

as a gathering place brings a certain continuity of purpose. The architectural theorist Brook Muller writes about the functional interplays between species in certain locals as creating a set of "richly interwoven coincidences," which resembles a singular purpose through the constellation of activities. ${ }^{22}$

The variety of over-lapping "uses" and "spaces" can get obscured with human concepts of ownership and property. The philosopher Carol Rose, refers to a defining quality of property to be able to signal themselves to the "relevant universe of nonowners." ${ }^{23}$ Certain human objects are owned and considered used, even when they are rarely actively used. For example, a deck maybe used for hours during summer days or evenings, but seasonality, weather, work and other life affairs reveal that products are used far less than the world would seem to imply. Yet, its upkeep would signify to others its ownership from other humans and the natural world. Therefore, untethering "ownership" from "actual use" reveals the true relationships humans have with their materials. Defining these staccato patterns of real use may also provide a way to intermingle uses with other non-human activities in the future.

Rose further explains that environmental resources are often "difficult to find recognizable markers," which leads to difficulty of defining property rights for humans. For wildlife, "ownership" is driven largely by use, and therefore when places are not in use, there is a likelihood of others to occupy them. The dependence on a woodpecker's cavities by certain bird and bat species is more than just a simple act of ownership transfer, but an important ecological process where objects are "improved" and passed down the line.

A diagram to express the use pattern of a multitude of species requires a representation of gathering and dispersion within a cycle. If a specie, such as a bat, utilizes a piece of wood for brooding or resting, they are using or borrowing it in a very succinct timeframe and then returning the object. A single deadcycle on a broader scale of time shows how these different uses have a natural sequence depending on the level of decomposition and successional position (see fig 5). For 


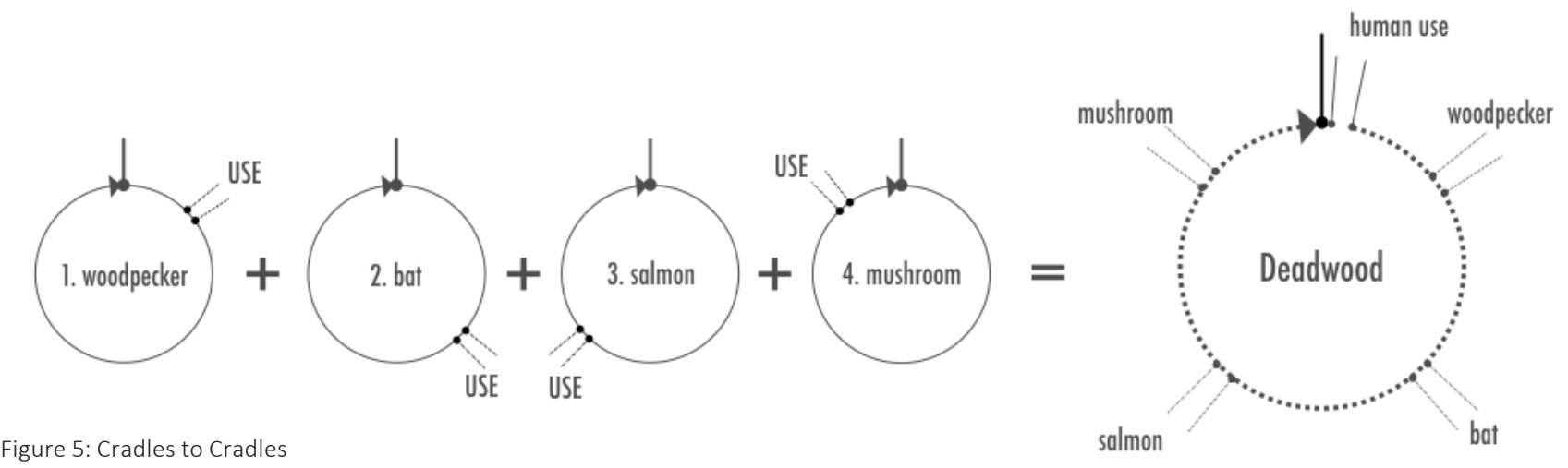

example, a woodpecker may first burrow a hole for itself in a snag - a standing deadtree - that then may be used by a bat for brooding which is still in the partially standing form, that then is latter used by salmon looking for shade in cooler waters once the wood has broken off into a riparian system, that then is finally devoured by decomposers like mushrooms. Although simplified, it shares how an organic material (like deadwood) may embody a multitude of cycles with some predictable level of sequence and defines a more diverse and pluralistic enduser perspective - a cradles to cradles.

The simultaneous and successional uses are key deadwood processes that celebrate the entropic process. These concepts are largely missing from the current $\mathrm{C} 2 \mathrm{C}$ model and, as shown earlier, instead tends to hasten entropy for the sake of human production and disincentives creative elongation of time and the emergence of latent interspecies cycles. Releasing human materials from the absolute ownership model to one of nibblings offers a significant potential to align more readily with ecological processes.

\section{BORROWED MATERAL \& PLACE}

An eco-material perspective should challenge designers to connect more directly to the ecological world. Climate change dialogs imply the need for great urgency and sweeping changes, yet the deadwood concepts suggests that drawing out processes is an important key to stimulate ecological processes. An approach that celebrate entropy is part of a growing provocation toward opposites in urban design, which echoes practical efforts like slowing hydrological systems and the many creative opportunities it brings. How can the deadcycle further inspire the architectural design process? How can designers adapt urban wood and the architectural object to be more inclusive of non-human processes? How can the current $\mathrm{C} 2 \mathrm{C}$ model adapt to include deadcycle considerations?

A final diagram for the deadcycle is one that inadequately illustrates both the elongation of time and the profusion of diverse uses. Yet, its values lie in maintaining a simple and intuitive entropic trajectory - the circle. The communion of many species using one object is, not surprisingly, about the importance of sharing, which implies a communal, ethical and relational perspective on ownership and stewardship. The environmental writer Wendell Berry describes those that share in these principles also understood, "that the world is not given by his fathers, but borrowed from his children." Although the deadcycle is concerned with the end-of-life, its deeper aim is to build a rich foundation for future relationships to prosper.

\section{ENDNOTES}

1 Michael Braungart, William McDonough, and Andrew Bollinger, "Cradle-toCradle Design: Creating Healthy Emissions-a Strategy for Eco-Effective Product and System Design," Journal of Cleaner Production 15, no. 13 (2007).

2 Ibid., 11.

3 David Abram, The Spell of the Sensuous: Perception and Language in a More-Than-Human World, 1st ed. (New York: Vintage Books, 1996). The environmental philosopher David Abram suggests that, "only by affirming the animateness of perceived things do we allow our words to merge directly from the depth of our ongoing reciprocity with the world."

4 Walter R Stahel, "The Product Life Factor," An Inquiry into the Nature of Sustainable Societies: The Role of the Private Sector (Series: 1982 Mitchell Prize Papers), NARC (1982): 72.

5 Ibid.

6 Ibid.

7 David Lindenmayer, Philip Joseph Burton, and Jerry F. Franklin, Salvage Logging and Its Ecological Consequences (Washington: Island Press, 2008), 13.

8 William McDonough and Michael Braungart, Cradle to Cradle: Remaking the Way We Make Things, 1st ed. (New York: North Point Press, 2002).

9 Ibid., 58.

10 Ibid., 53.

11 Abram, 56.

12 The Circular Economy document dedicates a section on, "how economies win - unlocking a multibillion USD (U.S. Dollar) opportunity, fast and lastingly," which reveals the impetus for speed and money to streamline materials. Ellen MacArthur, 66.

13 Nigel Dudley, Daniel Vallauri, and WWF France, "Deadwood - Living Forests," (Gland, Switzerland2004).

14 J.M. Marzluff and K. Ewing, "Restoration of Fragmented Landscapes for the Conservation of Birds: A General Framework and Specific Recommendations for Urbanizing Landscapes," Restoration Ecology 9, no. 3 (2001): 284.

15 H. Ronald Pulliam and Bart R. Johnson, "Ecology's New Paradigm: What Does It Offer Designers and Planners?," in Ecology and Design: Frameworks for Learning, ed. Bart Johnson and Kristina Hill (Washington, DC: Island Press, 2002), 51

16 Ibid.

17 Victoria Stevens, The Ecological Role of Coarse Woody Debris: An Overview of the Ecological Importance of Cwd in Bc Forests (British Columbia, Ministry of Forests, Research Program, 1997).

18 Society of American Foresters, "The Dictionary of Forestry," http://www. dictionaryofforestry.org/.

19 Crawford S Holling, "Understanding the Complexity of Economic, Ecological, and Social Systems," Ecosystems 4, no. 5 (2001): 391.

20 J.F. Franklin et al., "Disturbances and Structural Development of Natural Forest Ecosystems with Silvicultural Implications, Using Douglas-Fir Forests as an Example," Forest Ecology and Management 155, no. 1-3 (2002): 400.

21 Chris Maser et al., "Dead and Down Woody Material," in Wildlife Habitats in Managed Forests: The Blue Mountains of Oregon and Washington, ed. J. Louise Parker, et al. (Washington, D.C.: Wildlife Management Institute: U.S. Dept. of Interior For sale by the Supt. of Docs., U.S. G.P.O., 1979).

22 Muller echoes the work of Deleuze and Guattari on their phrase of "continuity of singularities," to show how the individual and collective processes relate and emerge in ecological processes. Brook Muller, Ecology and the Architectural Imagination (Routledge, 2014), 132.

23 Carol M Rose, "Liberty, Property, Environmentalism," Social Philosophy and Policy 26, no. 2 (2009): 14. 